\title{
Resistência de Cultivares e Linhagens de Tomateiro a Tomato chlorotic spot virus e a Potato virus $Y$
}

\author{
André L. Lourenção ${ }^{1 *}$, Walter J. Siqueira ${ }^{1}$, Arlete M. T. Melo ${ }^{1}$, Silvia R.L. Palazzo ${ }^{1 * *}$, \\ Paulo C.T. Melo ${ }^{2} \&$ Addolorata Colariccio ${ }^{3}$
}

${ }^{1}$ Instituto Agronômico, Cx. Postal 28, CEP 13001-970, Campinas, SP; ${ }^{2}$ Escola Superior de Agricultura Luiz de Queiroz, Cx. Postal 9, CEP 13418-900, Piracicaba, SP; ${ }^{3}$ Instituto Biológico, Cx. Postal 7119, CEP 01064-970, São Paulo, SP

(Aceito para publicação em 13/07/2005)

Autor para correspondência: André L. Lourenção

LOURENÇÃO, A.L., SIQUEIRA, W.J., MELO, A.M.T., PALAZZO, S.R.L., MELO, P.C.T. \& COLARICCIO, A. Resistência de cultivares e linhagens de tomateiros a Tomato chlorotic spot virus e a Potato virus Y. Fitopatologia Brasileira 30:609614. 2005.

\section{RESUMO}

Linhagens avançadas do programa de melhoramento do tomateiro (Lycopersicon esculentum) do IAC foram avaliadas em condições de campo em Campinas (SP) para resistência a tospovírus e a potyvírus, nos anos agrícolas 2002/2003 e 2003/2004, respectivamente. No primeiro ano, a única espécie de tospovírus que ocorreu na área experimental foi Tomato chlorotic spot virus (TCSV). As sete linhagens do grupo IAC exibiram baixa porcentagem de plantas sintomáticas em duas avaliações, com médias abaixo de $28 \%$; as cultivares testadas mostraram-se altamente suscetíveis, com médias acima de 85\%, à exceção de 'Franco', que apresentou cerca de 55\% de infecção. No segundo experimento, conduzido em 2003/2004, dez linhagens do grupo IAC foram comparadas com cinco cultivares de polinização aberta e híbridos $\mathrm{F}_{1}$, além do acesso LA-444-1 de L. peruvianum. Nesse experimento, por meio de testes biológicos e sorológicos, verificou-se ocorrência generalizada de Potato virus $Y$ (PVY). Foi determinado o percentual de plantas com sintomas e avaliada a intensidade dos sintomas mediante uso de escala de notas. Com base nos dois critérios, verificou-se que LA-444-1 apresenta alta resistência a PVY, que 'Tyrade' exibe comportamento intermediário, enquanto todos os demais genótipos demonstram alta suscetibilidade ao vírus. O comportamento dos genótipos avaliados neste trabalho mostra a necessidade de se considerar, nos programas de melhoramento do tomateiro, a introgressão de fatores de resistência não só a vírus de importância atual nas regiões produtoras, como geminivírus, mas também a outros vírus potencialmente nocivos à cultura, como tospovírus e potyvírus.

Palavras-chave adicionais: Lycopersicon esculentum, L. peruvianum, Tospoviridae, Potyviridae, resistência de plantas a doenças.

\begin{abstract}
Resistance of tomato lines and cultivars to Tomato chlorotic spot virus and Potato virus $\boldsymbol{Y}$

Advanced breeding lines from the IAC tomato breeding program and several tomato (Lycopersicon esculentum) cultivars and $\mathrm{F}_{1}$ hybrids were screened for tospovirus and potyvirus resistance under field conditions, at Campinas, São Paulo State, Brazil, during the 2002/2003 and 2003/2004 growing seasons. During the first season, only Tomato chlorotic spot virus (TCSV) was detected in plants of the experimental area. On both evaluations, all seven lines (IAC group) were resistant to TCSV, with under $28 \%$ of infected plants. The tomato cultivars and hybrids were highly susceptible, with greater than $85 \%$ of infected plants, except for 'Franco', with 55\% of infected plants. During the 2003/2004 growing season, the number of IAC lines evaluated was raised from seven to ten, and they were compared to five cultivars/ $F_{1}$ hybrids and to L. peruvianum LA-444-1. On this experiment, only Potato virus Y (PVY) was detected in plants. Evaluations were carried out using a symptom intensity scale and ELISA. Considering both criteria, it was verified that only LA-4441 displayed high resistance to PVY. In addition, 'Tyrade' displayed an intermediate behavior while all other lines, cultivars and hybrids behaved as susceptible to this potyvirus. These results highlight the need of introgressing resistance to multiple viruses in tomato breeding programs, taking into consideration the economical importance and relative incidence of each virus in different geographical regions and natural variations on incidence from year to year.
\end{abstract}

Additional keywords: Lycopersicon esculentum, L. peruvianum, Tospoviridae, Potyviridae, plant resistance.

\section{INTRODUÇÃO}

A produção de tomate (Lycopersicon esculentum Mill.) no Brasil em 2003 alcançou aproximadamente 3,5 milhões de toneladas, sendo a maior entre as hortaliças. No

*Bolsista do CNPq

**Aluna de Mestrado PG IAC, bolsista da Capes seu custo de produção, o uso de defensivos agrícolas atinge cerca de $9 \%$ do valor total dos insumos, constituindo-se importante componente do valor final do produto (Agrianual, 2004). Atualmente, considerável parte dos defensivos é utilizada visando ao controle de agentes vetores de vírus. Dentre as viroses ocasionadas por vírus transmitidos por vetores, destacam-se as causadas por vírus do 


\section{A.L. Lourenção et al.}

gênero Tospovirus, vírus da família Geminiviridae e com maior incidência nos últimos anos, vírus do gênero Potyvirus (Maciel-Zambolim, 2004)

Os tospovírus são importantes agentes fitopatogênicos em tomateiro nas épocas mais quentes do ano, em diversas regiões do mundo (German et al., 1992; Pozzer et al., 1996). São transmitidos por tripes pertencentes aos gêneros Frankliniella, Thrips e Scirtothrips, tendo sido relacionadas como vetoras dez espécies desses gêneros (Chen \& Chiu, 1996; Mound, 1996; Webb et al., 1998). Quatro espécies de tospovírus já foram identificadas no Brasil infetando tomateiros [Tomato spotted wilt virus (TSWV), Groundnut ringspot virus (GRSV), Chrysanthemum stem necrosis virus (CSNV) e Tomato chlorotic spot virus (TCSV)], sendo observada predominância de determinadas espécies de acordo com a região do país (Nagata et al., 1995; Ávila et al., 1998; Colariccio et al., 2000). No cinturão verde de Campinas, estado de São Paulo, por exemplo, nos últimos anos, a espécie TCSV tem predominado em plantas de tomateiro (Colariccio et al., 2000).

Os vírus do gênero Potyvirus, família Potyviridae causam em tomateiro um conjunto de sintomas envolvendo clareamento de nervuras, pontuações e mosaico amarelo e redução dos folíolos (Zerbini \& Maciel-Zambolin, 1999). Dentre os potyvírus, Potato virus $Y$ (PVY) é o que assume maior importância nessa cultura, sendo que sua gama de plantas hospedeiras está praticamente restrito à família Solanaceae (Zerbini \& Maciel-Zambolin, 1999). É o agente causador da doença 'risca-do-tomateiro', sendo transmitido por diversas espécies de afídeos (Costa et al., 1960). No Brasil, foram relatadas como vetoras as espécies Myzus persicae Sulzer, M. nicotianae Blackman, Aphis rumicis L. e Macrosiphum solanifolii Ashmead [= M. euphorbiae (Thomas)] (Costa et al., 1960; Cupertino et al., 1992, 1993). Isolados de PVY provenientes de batata são divididos em três subgrupos, com base em suas propriedades biológicas e sorológicas: $\mathrm{PVY}^{\mathrm{o}}, \mathrm{PVY}^{\mathrm{n}}$ e PVY ${ }^{\mathrm{c}}$. Entretanto, alguns isolados de batata (Solanum tuberosum L.), e isolados provenientes de outras espécies de plantas, incluindo o tomateiro, não são enquadrados em nenhum dos três subgrupos (Zerbini \& Maciel Zambolin, 1999). Nos últimos anos, a incidência de potyvírus tem aumentado em tomateiros nos estados de São Paulo e Espírito Santo (Palazzo et al., 2004; MacielZambolim et al., 2004). No Espírito Santo, uma nova espécie de potyvírus, Pepper yellow mosaic virus (PepYMV), foi relatado causando sérias perdas em tomateiro durante o ano de 2003 (Maciel-Zambolim et al., 2004). Para controle de doenças causadas por vírus, as principais medidas incluem o uso de sementes sadias ou material propagativo livre de vírus, prevenção da infecção por interrupção no plantio, erradicação de plantas com sintomas, controle de plantas da vegetação espontânea hospedeiras de vírus, prevenção na transmissão por vetores e melhoramento genético para introdução de resistência ao vírus, sendo este último indiscutivelmente o mais importante (Fraser, 1990). Assim, considerando-se a resistência varietal como o método mais eficiente de controle, objetivou-se no presente trabalho avaliar a resistência a tospovírus e a potyvírus em linhagens avançadas e em cultivares de tomateiros, em condições de infecção natural em campo, em Campinas (SP).

\section{MATERIAL E MÉTODOS}

\section{Avaliação da resistência a tospovírus (2002/2003)}

Avaliaram-se 16 genótipos, abrangendo sete linhagens provenientes do programa de melhoramento do tomateiro do IAC e nove cultivares (Tabela 1). Cinco linhagens foram selecionadas para resistência a tospovírus e a geminivírus ( $S w 5, T y-1)$, e duas apenas a tospovírus ( $S w 5)$ (Lourenção et al., 2004). Dentre as cultivares testadas, encontram-se híbridos comerciais resistentes a geminivírus ('Franco', 'Ty-Fanny' e 'Densus') e a cultivar IPA-5, considerada o controle suscetível.

A semeadura foi realizada em 22/11/2002, em bandejas de poliestireno expandido, com 128 células preenchidas com substrato Plantmax $®$. O transplante para campo foi efetuado em 13/12/2002, em área do Centro Experimental de Campinas, pertencente ao IAC. O delineamento foi de blocos ao acaso, com 16 tratamentos e cinco repetições. A parcela constituiu-se de duas linhas de 3 $\mathrm{m}$, com sete plantas por linha, num total de 14 plantas por parcela. $\mathrm{O}$ espaçamento entre linhas foi de $1 \mathrm{~m}$ e de $0,5 \mathrm{~m}$ entre plantas. A adubação foi feita na linha, empregando-se a fórmula 4-14-8, de acordo com análise de solo e recomendações para essa cultura (Raij et al., 1996). Utilizouse irrigação por gotejo sempre que necessário. Aos 27 e 66 dias do transplante para campo, respectivamente 44 e 83 dias após a germinação, procedeu-se à avaliação da incidência de tospovírus por meio da contagem de plantas com sintomas em toda a parcela, para obtenção da porcentagem de plantas sintomáticas.

\section{Identificação da espécie de tospovírus}

Para identificação das espécies de vírus presentes no experimento, foram realizadas coletas de ramos de tomateiros sintomáticos de cada parcela. As amostras foram submetidas a testes de microscopia eletrônica, testes de inoculação mecânica em plantas indicadoras (Chenopodium amaranticolor Coste \& Reyn, C. quinoa Wild, Cucurbita pepo L. 'Caserta', Capsicum annuum L. 'Magda', Datura stramonium L., Nicotiana tabacum L. 'White Burley', N. glutinosa L., N. megalosiphon Heurck \& Müll, L. esculentum 'Alambra') e testes sorológicos de DAS-ELISA com anti-soros contra as espécies TSWV, TCSV, GRSV e CSNV.

\section{Avaliação da resistência a potyvírus (2003/2004)}

Para este experimento, além das sete linhagens do experimento anterior, incluíram-se as linhagens IAC-1421, IAC-146-1 e IAC-146-2, portadoras dos genes $S w 5$ e $T y-1$, e LA-444-1 [Lycopersicon peruvianum (L.) Mill.], fonte de resistência a insetos e doenças (Lourenção et al., 1984; Nagai 
Resistência de cultivares e linhagens de tomateiros a...

et al., 1992). Também foram incluídas as cultivares Tyrade, Facundo e Stevens (Tabela 2), sendo utilizada 'IPA-5' como controle suscetível, e eliminadas as sete cultivares mais suscetíveis a tospovírus que participaram do ensaio conduzido no ano anterior $(2002 / 2003)$.
Realizaram-se a semeadura em 14/11/2003 e o transplante das mudas em campo 28 dias após. A área experimental, os procedimentos adotados de instalação, condução e delineamento foram idênticos aos do experimento anterior. Quarenta e cinco dias após o transplante (69 dias

TABELA 1 - Resultados de DAS-ELISA com anti-soros policlonais para identificação das espécies de vírus do gênero Tospovirus, em nove cultivares e sete linhagens de tomateiro (Lycopersicon esculentum), em condições de campo. Campinas, SP, 2002/2003

\begin{tabular}{llcccc}
\hline \hline \multirow{2}{*}{$\begin{array}{l}\text { Genótipo de } \\
\text { tomateiro }\end{array}$} & \multirow{2}{*}{ Genealogia } & \multicolumn{3}{c}{ Espécies de vírus do gênero Tospovirus* } \\
\cline { 3 - 5 } & & TCSV & TSWV & GRSV & CNSV \\
\hline IAC -S3 -318 & IAC-TySw5 x IAC -S4-3-18C & $2,8^{* *}$ & $0,9^{* *}$ & $1,2^{* *}$ & $0,2^{* *}$ \\
IAC -S4-3-18C & ('Stevens' x 'IPA6') x 'IPA6' & 1,1 & 1,9 & 1,8 & 1,5 \\
IAC-SVS -1 & ('Stevens' x 'IPA6')x 'IPA-6' & 2,9 & 0,3 & 1,2 & 0,1 \\
IAC-S3-54 & IAC-TySw5 x IAC -S4-4-16A & 4,5 & 0,7 & 1,1 & 0,4 \\
IAC -S3-29 & TWN-02/98 x IAC -TySw5 & 5,5 & 1,4 & 1,6 & 0,1 \\
IAC -S5-55-1 & Seleção de IAC-TySw5 & 9,4 & 0,1 & 1,8 & 0,4 \\
IAC -S3-16 & IAC-S4-4-16A x IAC -TySw5 & 5,3 & 0,2 & 1,4 & 1,8 \\
'Franco' & Portador do gene Ty-1 & 6,7 & 1,8 & 0,6 & 0,3 \\
'IPA -5' & & 5,4 & 0,2 & 1,2 & 0,1 \\
'Ty-Fanny' & Portador do gene Ty-1 & 2,4 & 0,5 & 1,2 & 0,7 \\
'AF -6692' & & 7,2 & 1,4 & 1,8 & 0,8 \\
'Densus' & Portador do gene Ty-1 & 4,6 & 1,5 & 1,8 & 0,5 \\
'AF -6698' & & 6,1 & 1,2 & 0,9 & 1,1 \\
'SS-560' & Portador do gene Ty-1 & 4,4 & 1,4 & 1,2 & 1,3 \\
'SS-569' & Portador do gene Ty-1 & 5,8 & 1,9 & 1,2 & 1,1 \\
'AF -5924' & & 4,6 & 0,6 & 0,5 & 0,7 \\
\hline
\end{tabular}

*TCSV - Tomato chlorotic spot virus; TSWV - Tomato spotted wilt virus; GRSV - Groundnut ringspot virus; CSNV-Chrysanthemum stem necrosis virus;

** Média das leituras $\left(\mathrm{A}_{405}\right)$ da amostra infetada sobre a sadia. Valores positivos: iguais ou superiores a três.

TABELA 2 - Resultados de PTA-ELISA com anti-soro policlonal para identificação de Pepper yellow mosaic virus (PepYMV) e de DAS-ELISA com anticorpos monoclonais para identificação das estirpes de Potato virus Y (PVY) em cinco cultivares e onze linhagens de tomateiro (Lycopersicon peruvianum), em condições de campo. Campinas, SP, 2003/2004

\begin{tabular}{|c|c|c|c|c|c|}
\hline \multirow{2}{*}{$\begin{array}{l}\text { Genótipo de } \\
\text { tomateiro }\end{array}$} & \multirow{2}{*}{ Genealogia } & \multicolumn{4}{|c|}{ Espécies de vírus do gênero Potyvirus* } \\
\hline & & PepYMV & PVY' & $P_{V Y Y}{ }^{N}$ & PVY ${ }^{C}$ \\
\hline LA-444-1 & (Lycopersicon peruvianum) & $0,6^{* *}$ & $1,9 * *$ & $0,8^{* *}$ & $1,2 * *$ \\
\hline 'Tyrade' & Portador do gene Ty -1 & 0,4 & 1,1 & 1,0 & 0,8 \\
\hline IAC -S3-54 & IAC-TySw5 x IAC -S4-4-16A & 0,8 & 5,1 & 1,1 & 0,9 \\
\hline IAC $-S 4-318$ & IAC-TySw5 x IAC -S4-3-18C & 1,3 & 4,8 & 1,1 & 1,7 \\
\hline IAC $-146-2$ & TWN-03/98 x IAC -TySw 5 & 0,6 & 4,4 & 1,5 & 1,1 \\
\hline IAC -S3-29 & TWN-02/98 x IAC -TySw5 & 2,0 & 1,3 & 1,2 & 1,2 \\
\hline IAC $-142-1$ & IAC-TySw5 x TWN -05/98 & 0,7 & 9,5 & 1,0 & 1,0 \\
\hline 'Facundo' & Portador do gene $T y-1$ & 0,4 & 4,8 & 0,8 & 1,2 \\
\hline IAC -S5-55-1 & Seleção de IAC-TySw5 & 1,2 & 7,8 & 1,0 & 0,8 \\
\hline IAC -S3-16 & IAC-S4-4-16A x IAC -TySw5 & 2,1 & 3,2 & 0,3 & 0,6 \\
\hline 'Franco' & Portador do gene $T y-1$ & 0,8 & 8,7 & 1,4 & 1,2 \\
\hline 'IPA -5' & (Lycopersicon esculentum) & 0,4 & 4,1 & 1,1 & 0,9 \\
\hline IAC $-146-1$ & TWN-03/98 x IAC -TySw5 & 4,5 & 9,3 & 1.9 & 1,5 \\
\hline 'Stevens' & (L. esculentum $\mathrm{x}$ L. peruvianum) & 2,1 & 6,3 & 0,7 & 0,6 \\
\hline IAC $-S 4-3-18 C$ & ('Stevens' x 'IPA-6') x ‘'IPA -6' & 2,0 & 5,4 & 0,9 & 1,2 \\
\hline IAC-SVS-1 & ('Stevens' x 'IPA-6') x 'IPA-6' & 0,6 & 5,5 & 1,7 & 1,4 \\
\hline
\end{tabular}

* PepYMV - Pepper yellow mosaic virus; PVY - Potato virus $Y$;

**Média das leituras $\left(\mathrm{A}_{405}\right)$ da amostra infetada sobre a sadia. Valores positivos: iguais ou superiores a três. 


\section{A.L. Lourenção et al.}

após a germinação das plantas), foi avaliada a incidência da doença mediante contagem de plantas sintomáticas em todas as plantas da parcela para obtenção da porcentagem de plantas doentes em relação às sadias. Ainda nessa data, avaliou-se a severidade da doença, atribuindo-se a cada planta uma nota de uma escala de 1 a 5 , onde 1 = ausência de sintomas; 2 = início de mosaico somente nas folhas apicais; $3=$ sintomas de amarelecimentos das nervuras com deformações dos folíolos apicais; 4 = sintomas de deformações dos folíolos até a região mediana, e $5=$ toda a planta com sintomas de amarelecimento e deformações dos folíolos.

\section{Identificação da espécie de potyvírus}

De cada parcela, foram coletados ramos de tomateiros com sintomas para identificação do vírus. As amostras foram submetidas a testes de microscopia eletrônica, testes de inoculação mecânica em plantas indicadoras ( $C$. amaranticolor, C. quinoa, C. pepo 'Caserta', C. annuum 'Magda', D. stramonium, N. tabacum 'White Burley', N. glutinosa, N. megalosiphon, L. esculentum 'Alambra') e testes sorológicos de DAS-ELISA com anti-soro monoclonal contra PVY ${ }^{0}$; PVY ${ }^{\mathrm{C}}$; PVYN (AGDIA) e PepYMV (InoueNagata, et al., 2001; Maciel-Zambolim et al., 2004).

\section{Análise estatística}

Os dados de porcentagem de plantas sintomáticas foram convertidos em arco seno $\sqrt{ } \% 100$ e os de nota em $\sqrt{x}$. Foram feitas análises de variância e as médias comparadas pelo teste de Tukey, ao nível de 5\% de probabilidade.

\section{RESULTADOS E DISCUSSÃO}

\section{Avaliação da resistência a tospovírus (2002/2003)}

A única espécie de tospovírus presente na área experimental nas duas avaliações foi TCSV (Tabela 1), repetindo a incidência ocorrida nessa mesma área no ano agrícola anterior, em experimento em que apenas essa espécie infetou tomateiros em processo de seleção (Lourenção et al., 2004). Na primeira avaliação, os índices médios de infecção variaram de 1,5\% (IAC-S5-55-1) a 44,6\% ('Densus') (Tabela 3). Houve discriminação da resistência, havendo um grupo com índices entre 1,5 e 5,7\%, formado por linhagens que vêm sendo selecionadas há vários anos para menor infecção por tospovírus e que apresentam em sua genealogia parentais com o gene $S w 5$, mais o híbrido Franco, e outro grupo com taxas médias oscilando de 29,2 a $44,6 \%$, e que inclui todos os demais genótipos comerciais. $\mathrm{Na}$ segunda avaliação, as linhagens IAC mantiveram as menores porcentagens de infecção, com valores médios entre 7,3 e $27,4 \%$ e diferindo de todas as outras cultivares, com exceção de 'Franco' (54,9\%). É interessante destacar que 'Franco', em experimento conduzido nessa mesma área em 2001/2002, teve baixo percentual de plantas infetadas com TCSV (13,7\%) quando comparado com a testemunha suscetível, 'IPA-5' (79,9\%) (Lourenção et al., 2004). Os híbridos AF-6692, AF-6698, AF-5924, SS-560 e SS-569, portadores de gene $T y-1$ que confere resistência a geminivírus (E.S. Matos, informação pessoal, 2004), juntamente com 'Ty-Fanny' e 'Densus', também resistentes a geminivírus, apresentaram na segunda avaliação médias de infecção por TCSV acima de 93\%. A introdução no mercado desses híbridos visou a enfrentar os surtos de geminiviroses que ocorreram em várias regiões brasileiras produtoras de tomate, ao final dos anos 90 e primeiros anos da nova década. Ocorre que, não possuindo resistência a tospovírus, podem se tornar material extremamente dependente de proteção contra vetores, principalmente de controle químico, no caso de alteração das espécies de vírus predominantes numa dada região.

\section{Avaliação da resistência a potyvírus (2003/2004)}

O potyvírus presente nesse experimento foi identificado como PVY estirpe comum $\left(\mathrm{PVY}^{\mathrm{O}}\right)$, que vem há cerca de três anos aumentando sua incidência em tomateiros em áreas experimentais do Centro Experimental de Campinas. A identificação do vírus foi realizada pela avaliação dos sintomas nas plantas indicadoras, que reagiram com ausência de sintomas em D. stramonium e C. annuum 'Magda', lesões locais em $C$. amaranticolor e sintomas sistêmicos de mosaico em N. glutinosa, N. tabacum 'White Burley', N. megalosiphon, com sintomas sistêmicos de mosaico amarelo generalizado e redução dos folíolos em 'Alambra' e pelo resultado positivo em DAS-ELISA contra o anti-soro para $\mathrm{PVY}^{\mathrm{O}}$ e negativo para PepYMV em PTA-ELISA (Tabela 2). Pelos resultados obtidos, pode-se concluir que a espécie de vírus que ocorreu no campo experimental do IAC foi PVYO e não PepYMV, pois as amostras não reagiram com o anti-soro para PepYMV, e plantas de $C$. annuum 'Magda' não manifestaram sintomas quando inoculadas com estes isolados. $\mathrm{O}$ vírus também não pode ser recuperado a partir de plantas de 'Magda'. Dentre as linhagens e cultivares avaliadas, só não reagiram positivamente em DAS-ELISA e PTA-ELISA o híbrido Tyrade e a linhagem IAC-S3-29, que obtiveram as menores médias e não apresentaram sintomas evidentes. Na avaliação de plantas com sintomas de PVY realizada 45 dias após o transplante, verificou-se, entre os tratamentos, a ocorrência de três grupos distintos: o primeiro, formado por LA-444-1 (L. peruvianum), em que se observaram poucas plantas sintomáticas; o segundo, formado por 'Tyrade', com cerca de $38 \%$ de plantas mostrando sintomas, e o terceiro grupo, envolvendo todas as linhagens IAC, juntamente com 'Facundo', 'Franco', 'IPA-5' e 'Stevens', com índices de plantas com sintomas variando de 86,8 a 98\% (Tabela 4). Com relação à intensidade de sintomas, avaliada mediante escala de notas de 1 a 5, observou-se gradiente maior entre os tratamentos; todavia, devem ser destacados novamente 'Tyrade', com nota média 2,58, e LA-444-1, com 1,04, que indica praticamente ausência de sintomas. Além da resistência observada em LA-444-1, outros acessos de $L$. peruvianum têm sido relacionados como resistentes a PVY: PI 126410, PI 128660 e PI 127829 (Nagai et al., 1991). A exemplo de outras doenças e pragas, acessos de L. hirsutum Humb. \& Bonpl. também foram relacionados como 
Resistência de cultivares e linhagens de tomateiros a...

TABELA 3 - Porcentagem média de infecção por Tomato chlorotic spot virus (TCSV) em nove cultivares e sete linhagens de tomateiro (Lycopersicon esculentum), em condições de campo. Campinas, SP, 2002/2003

\begin{tabular}{lcc}
\hline \hline Genótipo & \multicolumn{2}{c}{ Plantas com sintomas (\%) ${ }^{\mathbf{1}}$} \\
\cline { 2 - 3 } de tomateiro & 44 d.a.g. & $\mathbf{8 3 ~ d . a . g .} \mathbf{2}^{\mathbf{2}}$ \\
\hline IAC-S3-318 & $2,3 \mathrm{~b}$ & $7,3 \mathrm{~d}$ \\
IAC-S4-3-18C & $1,7 \mathrm{~b}$ & $8,2 \mathrm{~d}$ \\
IAC-SVS-1 & $4,6 \mathrm{~b}$ & $12,0 \mathrm{~d}$ \\
IAC-S3-54 & $5,3 \mathrm{~b}$ & $12,9 \mathrm{~d}$ \\
IAC-S3-29 & $3,1 \mathrm{~b}$ & $15,9 \mathrm{~d}$ \\
IAC-S5-55-1 & $1,5 \mathrm{~b}$ & $17,4 \mathrm{~d}$ \\
IAC-S3-16 & $5,7 \mathrm{~b}$ & $27,4 \mathrm{~cd}$ \\
'Franco' & $4,1 \mathrm{~b}$ & $54,9 \mathrm{bc}$ \\
'IPA-5' & $29,2 \mathrm{a}$ & $85,2 \mathrm{ab}$ \\
'Ty-Fanny' & $36,8 \mathrm{a}$ & $93,3 \mathrm{a}$ \\
'AF-6692' & $30,9 \mathrm{a}$ & $94,7 \mathrm{a}$ \\
'Densus' & $44,6 \mathrm{a}$ & $95,4 \mathrm{a}$ \\
'AF-6698' & $32,6 \mathrm{a}$ & $95,7 \mathrm{a}$ \\
'SS-560' & $37,6 \mathrm{a}$ & $96,6 \mathrm{a}$ \\
'SS-569' & $39,8 \mathrm{a}$ & $97,0 \mathrm{a}$ \\
'AF-5924' & $30,4 \mathrm{a}$ & $97,1 \mathrm{a}$ \\
\hline Média & 19,4 & 56,9 \\
C.V. (\%) & 32,44 & 18,13 \\
\hline
\end{tabular}

${ }^{1}$ Médias seguidas de mesma letra na coluna não diferem significativamente entre si pelo teste de Tukey a 5\%

${ }^{2}$ d.a.g. $=$ dias após a germinação

resistentes a PVY (Legnani et al., 1995), constituindo-se também em fontes de resistência a esse vírus. No caso de 'Tyrade', não é possível determinar qual a razão da ocorrência de um menor número de plantas sintomáticas nem da menor severidade de sintomas, uma vez que as informações disponíveis acerca de sua genealogia são de que se trata de híbrido portador do gene Ty-1 e selecionado para resistência a Tomato yellow leaf curl virus, família Geminiviridae, gênero Begomovirus (TYLCV) (E.S. Matos, informação pessoal, 2004).

Também para PVY, a constatação de que as linhagens atualmente em processo de seleção e, principalmente os híbridos disponíveis no mercado, são altamente suscetíveis a esse vírus, demonstra a vulnerabilidade da estratégia de se obter germoplasma apenas com resistência ao vírus de maior predominância e importância econômica numa dada área geográfica. O súbito reaparecimento de surtos de PVY em tomateiro no estado de São Paulo (Palazzo et al., 2004) nos últimos anos pode provocar mudanças nos programas de melhoramento dessa hortaliça, cuja ênfase no momento é a incorporação de resistência a Tomato yellow vein streak virus (TYVSV), família Geminiviridae, gênero Begomovirus, transmitido por moscas-brancas do complexo Bemisia tabaci Genn. Especificamente em relação ao PVY, nas décadas de 70 e 80, sempre houve disponibilidade para os produtores de cultivares que aliavam ótimas características agronômicas à resistência ao PVY, como 'Ângela' e 'IAC Santa Clara', obtidas pelo programa de melhoramento do IAC (Nagai et
TABELA 4 - Porcentagem média de infecção e notas médias ${ }^{1}$ de avaliação de sintomas causados por Potato virus $Y\left(\mathrm{PVY}^{\circ}\right)$ em cinco cultivares e 11 linhagens de tomateiro (Lycopersicon peruvianum), em condições de campo. Campinas, SP, 2003/2004

\begin{tabular}{lcc}
\hline \hline \multirow{2}{*}{$\begin{array}{l}\text { Genótipo de } \\
\text { tomateiro }\end{array}$} & $\begin{array}{c}\text { Plantas com } \\
\text { sintomas (\%) }\end{array}$ & Notas $^{\mathbf{1}, \mathbf{2}}$ \\
\cline { 2 - 3 } & \multicolumn{2}{c}{ 69 d.a.g. } \\
\hline LA-444-1 & $0,1 \mathrm{a}$ & $1,04 \mathrm{f}$ \\
'Tyrade' & $38,5 \mathrm{~b}$ & $2,58 \mathrm{e}$ \\
IAC-S3-54 & $88,4 \mathrm{c}$ & $3,74 \mathrm{~d}$ \\
IAC -S4-318 & $87,6 \mathrm{c}$ & $3,88 \mathrm{~cd}$ \\
IAC-146-2 & $93,1 \mathrm{c}$ & $4,12 \mathrm{bcd}$ \\
IAC-S3-29 & $94,3 \mathrm{c}$ & $4,22 \mathrm{abcd}$ \\
IAC -142-1 & $86,8 \mathrm{c}$ & $4,44 \mathrm{abcd}$ \\
'Facundo' & $97,0 \mathrm{c}$ & $4,54 \mathrm{abc}$ \\
IAC-S5-55-1 & $91,9 \mathrm{c}$ & $4,58 \mathrm{abc}$ \\
IAC-S3-16 & $92,4 \mathrm{c}$ & $4,70 \mathrm{ab}$ \\
'Franco' & $92,3 \mathrm{c}$ & $4,70 \mathrm{ab}$ \\
'IPA -5' & $89,0 \mathrm{c}$ & $4,82 \mathrm{ab}$ \\
IAC-146-1 & $93,8 \mathrm{c}$ & $4,82 \mathrm{ab}$ \\
'Stevens' & $95,9 \mathrm{c}$ & $4,88 \mathrm{a}$ \\
IAC-S4-3-18C & $96,6 \mathrm{c}$ & $4,92 \mathrm{a}$ \\
IAC SVS 1 & $98,0 \mathrm{c}$ & $4,94 \mathrm{a}$ \\
\hline Média & 83,5 & 4,18 \\
C.V. (\%) & 13,90 & 7,93 \\
\hline
\end{tabular}

${ }^{1}$ Médias seguidas de mesma letra na coluna não diferem significativamente entre si pelo teste de Tukey a $5 \%$.

${ }^{2}$ Escala de notas de 1 a 5 , onde 1 = ausência de sintomas na planta, 2 =. início de mosaico somente nas folhas apicais; $3=$ sintomas de amarelecimentos das nervuras com deformações dos folíolos apicais; 4 = sintomas de deformações dos folíolos até a região mediana, e $5=$ toda a planta com sintomas de amarelecimento e deformações dos folíolos

${ }^{3}$ d.a.g. $=$ dias após a germinação

al., 1991), o que já não acontece no Brasil há vários anos. Assim, deve ser considerada a possibilidade de introgressão de fatores de resistência em tomateiro não só a geminivírus, que nos últimos anos tem sido referido como um dos fatores limitantes de produção dessa hortaliça, mas também a outras doenças causadas por potyvírus e tospovírus.

\section{AGRADECIMENTOS}

Os autores agradecem ao Dr. José Alberto Caram de Souza Dias (IAC) e ao Dr. Antonio Carlos de Ávila (Embrapa Hortaliças) pelo fornecimento de anti-soros para identificação de PVY e tospovírus, respectivamente, e ao Dr.Hugo Kuniyuki (IAC) e ao Dr. Jorge Alberto Marques Rezende (ESALQ) pela revisão crítica do texto.

\section{REFERÊNCIAS BIBLIOGRÁFICAS}

AGRIANUAL-Agrianual. Anuário da Agricultura Brasileira. FNP Consultoria e Agroinformativos, São Paulo, 496p. 2004.

ÁVILA, A.C., POZZER, L., BEZERRA, I., KORMELINK, R., PRINS, M., PETERS, D., NAGATA, T., KITAJIMA, E. \& 
RESENDE, R. Diversity of tospoviruses in Brazil. In: INTERNATIONAL SYMPOSIUM ON TOSPOVIRUSES AND THRIPS IN FLORAL AND VEGETABLE CROPS, 4., Wageningen: Abstracts... pp.32-34. 1998.

CHEN, C.C. \& CHIU, R.J. A tospovirus infecting peanut in Taiwan. Acta Horticulturae 431:57-67. 1996.

COLARICCIO, A., EIRAS, M., CHAVES, A.L.R., LOURENÇÃO, A.L., MELO, A.M.T. \& SIQUEIRA, W.J. Detecção do 'Chysanthemum stem necrosis virus' em tomateiro no Estado de São Paulo. Summa Phytopathologica 25: 252-254. 2000.

COLARICCIO, A., EIRAS, M., CHAVES, A.L.R., ROGGERO, P. \& CHAGAS, C.M. Diversidade de tospovírus em diferentes regiões produtoras de olerícolas do Estado de São Paulo. Summa Phytopathologica 27:177-182. 2001.

COSTA, A.S., CARVALHO, A.M.B. \& KITAJIMA, E.W. Risca do tomateiro em São Paulo, causada por estirpe do vírus Y. Bragantia 19:1111-1128. 1960.

CUPERTINO, F.P., COSTA, C.L., MELO, A.B.P., SUDO, S \& SILVA, A.M.R. Transmissão de estirpes de PVY vindas de batata, pimentão ou tomate por meio de Myzus persicae. Fitopatologia Brasileira 17:187. 1992. (Resumo)

CUPERTINO, F.P., COSTA, C.L \& SILVA, A.M.R. Transmissão de três estirpes do vírus Y da batata por Myzus nicotianae. Fitopatologia Brasileira 18:102-106. 1993.

FRASER, R.S.S. The genetics of resistance to plant viruses. Annual Review of Phytopathology 28:179-200. 1990

GERMAN, T.L., ULLMAN, D.E. \& MOYER, J.W. Tospoviruses: diagnosis, molecular biology, phylogeny, and vector relationships. Annual Review of Phytopathology 30:315-348. 1992.

LEGNANI, R., SELASSIE, R.G. WOMDIM, R.N., GOGNALONS, P., MOTTI, A., LATERROT, H. \& MARCHOUX, G. Evaluation and inheritance of the Lycopersicon hirsutum resistance against potato virus Y. Euphytica 86:219-226. 1995.

LOURENÇÃO, A.L., NAGAI, H. \& ZULLO, M.A.T. Fontes de resistência a Scrobipalpula absoluta (Meyrick, 1917) em tomateiro. Bragantia 43:569-577. 1984.
LOURENÇÃO, A.L., MELO, A.M.T., SIQUEIRA, W.J., COLARICCIO, A. \& MELO, P.C.T. Avaliação da resistência de acessos de tomateiro a tospovírus e a geminívirus. Horticultura Brasileira 22:192-195. 2004.

MACIEL-ZAMBOLIM, E., COSTA, H., CAPUCHO, A.S., ÁVILA, A.C., INOUE-NAGATA, A.K. \& KITAJIMA, E.W. Surto epidemiológico do vírus do mosaico amarelo do pimentão em tomateiro na região serrana do Espírito Santo. Fitopatologia Brasileira 29:325-327. 2004.

MOUND, L.A. The Thysanoptera vector species of Tospoviruses. Acta Horticulturae 431: 298-307. 1996.

NAGAI, H., LOURENÇÃO, A.L. \& SIQUEIRA, W.J. Tomato breeding for resistance to diseases and pests in Brazil. Acta Horticulturae 301:91-97. 1992.

NAGATA, T., ÁVILA, A.C., TAVARES, P.C.M., BARBOSA, C.J., JULIATTI, F.C. \& KITAJIMA, E.W. Occurrence of different tospoviruses in six States of Brazil. Fitopatologia Brasileira 20:9095. 1995.

PALAZZO, S.R.L., BERGMANN, J.C., CHAVES, A.L.R., EIRAS, M., CHAGAS, C.M. \& COLARICCIO, A. Surto de Potyvirus associado ao mosaico amarelo do tomateiro no Estado de São Paulo. Summa Phytopathologica 30:117. 2004. (Resumo)

POZZER , L., RESENDE, R.O., LIMA, M.I., KITAJIMA, E.W., GIORDANO, L.B. \& ÁVILA, A.C. Tospovírus: uma visão atualizada. Revisão Anual de Patologia de Plantas 4: 95-148. 1996.

RAIJ, B., CANTARELla, H., QUAGGIO, J.A. \& FURLANI, A.M.C. Recomendações de adubação e calagem para o Estado de São Paulo. Campinas: Instituto Agronômico - Fundação IAC, Boletim Técnico, 100, 1996.

WEBB, S., TSAI, J. \& MITCHELL, F. Bionomics of Frankliniella bispinosa and its transmission of tomato spotted wilt virus. In: International Symposium on Tospoviruses and Thrips in Floral and Vegetable Crops, 4, Wageningen: Abstracts...p.67. 1998.

ZERBINI, F.M. \& MACIEL-ZAMBOLIM, E. A família Potyviridae - Parte I. Revisão Anual de Patologia de Plantas 7:166. 1999. 